\title{
Beyond Narratology: David Foster Wallace's Infinite Jest
}

\section{Richard Stock}

David Foster Wallace's Infinite Jest (1996) provides a fruitful test case for what we can accomplish with the traditional analysis of narrative and novels. As a method to study storytelling, narratology has flourished in the twentieth century and has been the dominant way to study narrative. In this paper, I focus on Gerard Genette as the progenitor of narratology, along with Peter Brooks's more recent attempt at re-directing narratology. Using these important examples, which focus on the novel as the prime example of narrative, I claim that narratology fails to account for many instances of narrative that we encounter today - especially novels - and that narratology fails at its own basic goal. This is shown palpably in a small but telling example from David Foster Wallace's Infinite Jest. Through this reading, I demonstrate that narrative theory and the study of the novel has not changed since its inception several decades ago. This is not necessarily for bad reasons, but the field should consider iffor the $21^{\text {st }}$ century the field needs to reconsider the theoretical bases it is founded on, perhaps by studying novels like Infinite Jest in a different way.

\section{Introduction}

The twentieth century saw a rather astonishing development of scholarly study related to stories and to storytelling. In this study, I focus on Gerard Genette as the initiator of a certain persistent type of narratology and Peter Brooks as a more recent attempt at revising that approach. I claim that the narratology that we typically practice - which began with Genette and was not successfully revised for the late $20^{\text {th }}$-century world by Brooks - fails to account for many instances of narrative that we encounter, especially in the later part of the $2 \mathrm{O}^{\text {th }}$ century and now in the $21^{\text {st }}$. The second part of this study uses a small example from David Foster Wallace's Infinite fest to illustrate this claim.

I imply that narrative theory, while discussed in different terms by different thinkers, as a theory has not changed since its inception several decades ago. This is not necessarily for bad reasons, but those interested in the theory and 
practice of narrative in the $21^{\text {st }}$ century should consider if the field needs to again take on a "vertical" orientation, and reconsider the theoretical bases it is founded on.

\section{Narratology}

The history of the study of narrative has been detailed in various works with various approaches. Peter Brooks's review in Reading for the Plot: Design and Intention in Narrative (1984) starts before "narratology" existed, explaining the influence of scholars like Vladimir Propp, progressing to the creation of narratology with the likes of A. J. Greimas and Tzvetan Todorov, and ending up with Roland Barthes's attempts to make explicit the assumptions of narratology. To understand these efforts, Brooks proposes a "horizontal" versus a "vertical" orientation to the study of narrative. People like Propp did "horizontal" work, looking for similarities across examples. Barthes, on the other hand, is the best example of a "vertical" scholar, going deeply into individual texts, trying to unearth a hidden foundation common to all narrative. In both cases, the effort is to try to find what is usually referred to as a "grammar" of narrative. The goal is to identify the system by which ubiquitous storytelling operates. This assumes that such a system exists, which seems reasonable since so many people rely so much on stories, and understand the same stories in similar ways.

Gerard Genette's Narrative Discourse (1972) is arguably the source most referred to in narratology. In fact, its influence is so pervasive that many of the terms Genette pioneers in this work have long been used in common circulation, and are no longer referenced back to their source. Terms like "focalization" (189) and the plethora of terms using "diegetic" as a root, such as "extradiegetic", "intradiegetic", and "metadiegetic" (128), are used as Genette defined them, without recognizing the original source. It is striking how quickly this happened.

Jonathan Culler claims that Genette's task was to apply a narrative to narratology: "The structures and codes which Barthes and Todorov studied must be taken up and organized by a narrative; this activity is Genette's subject" (8). Genette creates a system of codes and terms for each code by which we can efficiently discuss narrative. Because of this, his work is more than anything a toolbox, but one that we are indebted to even in studies that do not share the narratological assumptions that Genette uses. One of the most 
striking effects of Genette's study is how it implicitly exposes the complete lack of a common vocabulary and the connected set of common concepts to discuss narrative. Even after Genette, we still struggle with this problem. Often our debates about narrative are little more than opposing salvos on what certain terms should mean, rather than more substantive discussions of how (or why) narrative works (or can work).

One good example is Genette's discussion of how we should define and discuss the "duration" of a narrative in temporal terms. Genette acknowledges that this is not a simple matter:

Comparing the "duration" of a narrative to that of the story it tells is a trickier operation, for the simple reason that no one can measure the duration of a narrative. What we spontaneously call such can be nothing more, as we have already said, than the time needed for reading; but it is too obvious that reading time varies according to particular circumstances. (86)

Indeed, it is rather obvious and important that the comparison between how much time a story encompasses and how long it takes to read the narration of that story can be a crucial aspect of an analysis of narrative. Genette is correct to point out that we simply lack a standard by which to agree on what is a "longer" or "shorter" duration of narrations of a particular story. But, it is also clear that there is some level of agreement on a standard relation between the time of the story and the time of reading. So, Genette takes recourse to a general definition, thus: "the speed of a narrative will be defined by the relationship between a duration (that of the story, measured in seconds, minutes, hours, days, months, and years) and a length (that of the text, measured in lines and in pages)" (87-88). This is perhaps practically reasonable given the inherent difficulties, but it still does not give us any guidance as to how to discuss duration or to define what duration really is. Further, it does not really set a standard for comparison, since "lines" or "pages" are obviously not standard units of measurement. It just nods to the difficulty of establishing codes and names for codes, but then goes ahead and establishes and names them anyway. This does not resolve or even deal with the difficulty. In doing this Genette has to make implicit, unsupported (and unsupportable) assumptions about narrative.

Other useful concepts that Genette establishes include the basic idea that a narrator always exists on a level above the story (228). Nothing specific 
can be said about exactly how many, or what kind of levels, there are in a story (or how they change or are indeterminate). For this idea to work there has to be a hierarchy of narrative levels, with one "narrator" at the top. This basic idea is important to be able discuss narrative efficiently. Focalization is another term that Genette invents (189), one that makes intuitive sense and that is useful in discussing narrative. However, he simply denies that, even though the concept of focalization makes sense, there will be things we want to call narratives and stories that do not play by the rules of focalization that he establishes.

All of the terms that Genette establishes, and by extension his very system of terms, fall prey to this basic shortcoming. In order to create the system, Genette is forced to make strong assumptions about the character of narrative. He must hold narrative stable in one particular definition in order to reason out why the terms he sets are workable and integrated into a coherent whole. He must assume, for example, that stories are often told by the reader "seeing through" a particular character and/or narrator, and therefore the concept of focalization is reliable. However, from today's perspective it is relatively easy to think of alternative ways of understanding how a story is told than through focalization as Genette describes it.

The "Afterword" to Narrative Discourse expresses a hope that this toolbox will serve the "scientific" goal of not being completely correct, but rather as a basis for progress. He hopes that the "technology" in the book "tomorrow will seem positively rustic, and will go to join other packaging, the detritus of Poetics" (263-264). However, the follow-up Narrative Discourse Revisited (1983) engages in the curious project of correcting criticisms of the earlier work. In Narrative Discourse Revisited Genette shows that works of narratology really do in the end want to provide an absolute, complete description of narrative, and are frustrated when others claim that their works do not reach this goal. Later in this paper I show that one of the reasons why Genette's first work has not joined the "detritus of Poetics" is because his toolbox is impossible to prove wrong.

\section{After narratology but still narratological}

While there have not been any systematic attempts at a theory of narrative since Genette, there have been book-length studies of narrative with different goals. These studies are still in the narratological tradition, and the fact that 
Genette's toolbox continues to be used more than any other work since indicates that the field has not progressed. Peter Brooks's Reading for the Plot: Design and Intention in Narrative (1984) is one of the more recent book-length studies devoted to narrative (even though it is by now almost 30 years old). I use this text as an example to illustrate that such works since Genette claim to go beyond narratology, but retain the "grammar of narrative" motivation present since Greimas.

In this book, Brooks calls for a renewed focus on "plot" in studying narrative and stories. Brooks's turn to plot seems to be in reaction to the obvious and predictable failure of structuralists like Genette to describe narrative in a reliable way. Those studying narrative from the mid-198os onward have an uneasy relationship with structuralist efforts at narrativity. Almost universally they claim that narratologists performed a necessary and important task in attempting to create a universal grammar or structure of narrative. But they also almost universally state that the project has failed. Brooks is in this group, and he turns his attention away from the "impossibly speculative task to say what narrative itself is" toward thinking about "the kinds of ordering it uses and creates, about the figures of design it makes" (4). The best way to do this, Brooks claims, is to renew attention to plot. This is certainly a valid effort, to fill in the gap left by narratologists' failure, and the choice of plot seems fruitful and innovative. Unfortunately, in the end, Brooks's work on plot is in effect squarely in the narratologist tradition that he claims has failed at its own goal. But it is important that Brooks sees a need to try to create a narratology that avoids this failure: it shows that there is a need for a new study of narrative.

However, Brooks's choice to focus on plot is not a benign one. Shlomith Rimmon-Kenan, in Narrative Fiction: Contemporary Poetics (1983) all but ignores plot, even though the volume is a respected review of narrative theory and criticism. In Reading for the Plot, Brooks claims that plot is actually the basis for narrative, the necessary component to call anything a story: "Plot is $[\ldots]$ a constant of all written and oral narrative, in that a narrative without at least a minimal plot would be incomprehensible. Plot is the principle of interconnectedness and intention which we cannot do without in moving through the discrete elements [...] of a narrative" (5). In other words, without plot, the text is not a narrative, and plot has to do with connecting different parts of that narrative and expressing an intention.

Brooks takes pains to emphasize that his motivation is not structuralist. $\mathrm{He}$ is not trying to identify a universal use of plot in different works. Rather, he 
is interested in defining and understanding plot as a motivation for narrative through various examples. "Plot as it interests me is not a matter of typology or of fixed structures, but rather a structuring operation peculiar to those messages that are developed through temporal succession, the instrumental logic of a specific mode of human understanding" (10). The effort here is not to get to a "deep structure" in the structuralist sense of a general formal structure of narrative that repeats in many different and various works and forms an organic basis of our concept of narrative. Rather, Brooks is more literally looking deeper into the "structure" of narrative, looking for what motivates and generates whatever formal structure of narrative gets produced. He calls plot the "logic and dynamic of narrative" (10), showing that while we can perhaps study plot and discuss it as a concept, we cannot identify a stable structure of plot. Therefore, Brooks's purpose is more philosophical, in defining and discussing a concept that can then be used by others in their thinking about narrative and narratives.

Above we can already see one important defining aspect of plot and narrative for Brooks: "temporal succession" and this being linked to a certain kind of "human understanding". In the end this is a large assumption in this book, which generally disregards the huge body of research on the problem of humans' relationship with time. Brooks broadly assumes a chronological structure, interpreting a second event in a story differently than the first event in naturally seeing a progression and causality in the time elapsed. Brooks sees this as the human need to plot, that we look for meaning in events ordered in a temporal sequence. Brooks's study, as a more philosophical approach to narrative if not a philosophical tract, has to ignore much philosophical work of the twentieth century to maintain such a simple conception of time. For example, Paul Ricoeur's three-volume Time and Narrative (1983-1985) is a study of narrative that pays much closer attention to the problems and possibilities that the conundrum of time presents to writers and to readers, drawing on philosophical approaches to time from the $20^{\text {th }}$ century.

The problematic approach to time and human understanding also causes Brooks to have a problematic approach to ends and to beginnings. Brooks asserts that narrative depends on a stable understanding of beginnings and ends: "The authority of narrative derives from its capacity to speak of origins in relation to endpoints" (276). His example here is Sigmund Freud's narration of the Wolf-Man case. This is a carefully chosen "real-life" example, where a narrative refuses to play by its own rules or the rules of narratology. Instead of investigating what that means for storytelling or narratology, Brooks claims 
that "the case history of the Wolf Man shows up the limits of storytelling while nonetheless insisting that the story must get told. [...] But if plot has become an object of suspicion, it remains no less necessary: telling the self's story remains our indispensable thread in the labyrinth of temporality" (284-285). Most of Brooks's analysis here is useful, up to the point where he claims that such problems insist "that the story must get told".

Brooks is not alone in this logical flaw; many others make similar claims. Stories should communicate with people by adhering to an implicit contract between the text and the reader. This contract involves the origin (the text, the author) and the endpoint (the reader). He shows a story that does not play by its own rules, that breaks the contract. By breaking the rules the story threatens to destroy itself. Yet the story is still read and understood by many people. It is a puzzle how people understand a story that breaks the contract. The solution to the puzzle is that people need narrative so badly they will accept even a story that breaks its own rules. This is not really a solution, of course, but rather a rejection of the whole logical construct of the contract and the rules that narrative is supposed to follow.

The logic that Brooks uses is that as humans we have a drive to seek out origins and endpoints. Narrative promises such origins and endpoints, and this is why we are attracted to narrative. But in the final analysis (and with no surprise in today's world), narrative does not really provide origins or endpoints. But we keep on needing stories. So our need for origins and endpoints must be so great, and our options to get at them so few (in fact barren except for narrative), that even when narrative explicitly says one thing and does another, we have to accept it. As a logic, this simply refuses the possibility of a counter-example.

This motivates me to wonder if there are other reasons why narrative works the way it does, and other reasons why we are able to understand narratives in the way we do. Could it be that we need narrative, plotting, and stories because we do not really need origins or endpoints? There is plenty of empirical evidence that humans are indeed attracted to narrative, to such an extent that we could call it a need. That point cannot be debated. But what drives that need, if it is not a need for origins and endpoints? Brooks tries to imply, instead of argue, that the only answer to this question is: nothing. Could it be that we need narrative for another reason, a reason that is not so blatantly violated by Freud's account of the Wolf-Man or any number of modernist and postmodernist novels? Could it be that we need narrative for the process of reading and understanding a story itself, rather than what that 
reading and understanding will then (in another kind of temporal succession) bring us?

Brooks is enough in contact with philosophy of the last two hundred years to see that a focus on time is also a focus on ends, and the most obvious end of all, death. So he specifies his definition of plot not just as having to do with time, or a human conception of a progression of time and causality, but the following: "It is my simple conviction, then, that narrative has something to do with time-boundedness, and that plot is the internal logic of the discourse of mortality" (22). This conclusion is not unique to Brooks; indeed he quotes Walter Benjamin to support his point, and other literary critics such as Frank Kermode have made much of narrative's relation to death. In Kermode's The Sense of an Ending (1966), he not only links narrative to death, but to a particular need to understand the apocalypse, in a sense the ultimate death. One of Kermode's most interesting insights is that this drive through narrative to understand death causes each current period to be seen by the humans living in that time as a "transition" period. That is, it is not an end, it is not a beginning, but rather coming from a beginning and going towards an end.

To come to his conclusion, Brooks has to twist Roland Barthes's idea of le passion du sens (in both the sense of a passion for meaning and a passion of meaning) into a passion for an end, and the ultimate end of death. Brooks defines Barthes's le passion du sens as "the active quest of the reader for those shaping ends that, terminating the dynamic process of reading, promise to bestow meaning and significance on the beginning and the middle" (19). He does claim that he "extrapolates" from Barthes; the question is to what degree, and if the extrapolation is justified. Here Brooks slides without explanation or justification from "meaning" to "end", which to my mind needs more support. It is not clear to me why a passion for meaning cannot be a passion for engaging in a process, a passion for gaining tentative knowledge, a passion for learning how to live rather than what happens when we die. Similarly, it is not clear to me in Kermode's The Sense of an Ending why we do not perpetually see ourselves as in a transition period - in a middle period, in process between unknowable beginnings and endings - because that is where we want to be, that is where we are most comfortable. We are most comfortable there because we cannot be anywhere else. Without this understanding of narrative as the necessary in-between, Brooks's yearning in narrative for an impossible approximation of death and Kermode's perpetual transition periods are negative and hopeless places to be. 
Much of Reading for the Plot is plagued by this useful but also problematic reference to temporal progression and necessary ends. Another broad assumption of the book is that each narrative has a neat beginning, middle, and end. That is, his assumptions about origins and endpoints are not just about narrative in general, but also about the literal beginning and end of a narrative text. Brooks writes of a "desire [that] is always there at the start of a narrative" $\left(3^{8}\right)$ and even more he refers to the "end" of a narrative. "If at the end of a narrative we can suspend time in a moment when past and present hold together in a metaphor $[\ldots]$ that moment does not abolish the movement, the slidings, the mistakes, and partial recognitions of the middle" (92). In reference to Roquentin (and implicitly Kermode), he concludes that "the sense of a beginning, then, must in some important way be determined by the sense of an ending" (94) because there can be no end without a beginning and vice versa. Essentially, the beginning is desire, the end is death, and the middle is "obscure" (96). There are two problems here to my mind. First, where are the beginning and end? Second, why do we need to define and resolve these to discuss the middle?

It seems to me that what Brooks has to say about the middle is the most interesting part of his beginning-middle-end structural assumption. Indeed, the middle is "obscure", but it is also the only component of this triad that we can compare to lived life, that coincides with our lived temporal frame. Using the novel as his example of narrative, the assumption Brooks seems to have is that the moment you read the first word of the novel is the beginning, and the moment you read the last word is the end. Indeed, in the conclusion to the book, in the midst of a useful questioning of ends - "Ends, it seems, have become difficult to achieve" (313) - Brooks uses the book as the only end (and therefore beginning) we can count on: "Yet they take place: [...] we have no more pages to read" (314).

It is rather easy to criticize this in practical terms, even assuming Brooks's model of the novel as narrative, and this goes beyond a simple consideration of paratexts. When I first hear about a novel, or when I hear someone mention the title and author, have I begun? When I hear someone summarize the book, or when I read a summary or review, have I begun? If I then go to read the book itself, is my reading of the first word, when I already know the broad outline of the book, really the beginning? What if the book is by an author who I know, whose works I have read before? Is my beginning the same as a reader who does not know the author? What if I am completely 
ignorant about the novel before I read the first word (an almost impossibly rare occurrence): if I know the book is a novel, is reading the first word really a fresh beginning?

Similar questions can be asked about the "deathlike ending". When I finish the last word, but then turn back and re-read a chapter, what is the ending? What if the book encourages me to think further about the content, where is the end? What if, in fact, the book requires me to re-read and think further to make meaning from the book? If the book encourages me to remember, to think again, to re-read, to construct my own meanings from the components the book provides, how is this deathlike? How does this serve the supposedly basic human purpose of dealing with death, other than perhaps avoiding it? Even more typically, what if I finish the book, then months later engage in a discussion with someone about the book whereby I modify my evaluation or experience of the story, where is the end?

Admittedly, these questions could be erased by claiming that it is the concept of beginning and ending that is important, so that any one assignation of beginning or ending would suffice. But Brooks does not have this conception, with his "we have no more pages to read" (314), and he is rather typical in this assumption of a linear first-page-to-last-page process of "reading" a narrative. The assumption is typical because no other consistent way to consider beginnings and ends exists.

I propose that at least in the time since Brooks's study, we have begun to forget about death. Positioning narrative as beginning with desire for knowledge about death and ending with something approximating death makes narrative merely a coping mechanism. By now we have to know that no matter how well we tell stories, how well we try to understand and cope with death, that we can have no hope to mitigate the surprise at what death will bring. It seems to me that culturally we have found it necessary to forget about death, and let it be an outside, an unknown, and turn to making meaning to inform the lives we live rather than to explore death.

Brooks had a noble aim in Reading for the Plot: to bring us to a narratology that has lived and learned from the structuralist attempt and failure. His focus on plot as a narrative concept through which to think about narratives, rather than a template by which to analyze narratives, is most useful in its general motivation, to be such a "thinking through" concept, and less useful in delineating a particular understanding of "plot". However, several of the defining aspects of plot, even as a "thinking through" concept, remain 
problematic and refer to a rather traditional understanding of concepts such as temporality, beginnings, and endings. This is the case even though in some places Brooks makes statements that seem free of this dependence, because more often in his description of his ideas he falls back on these traditional conceptions. To some extent Brooks just does not do what he says he will do.

It seems to me that we are now more comfortable with a looser dependence on certain beginnings and endings, and that while we do retain some concept of beginning and ending, by now our dependence on such concepts is so tenuous that it is not really worth thinking about the "middle" in terms of the "end". I would like to propose that this is analogous to a looser conception of temporality than Brooks and others rely on in discussing narrative, or perhaps a more philosophical consideration of temporality. It is a well-known facet of narrative that it depends on some conception of the passage of time; that events can be ordered in a linear fashion. But it is also a well-known facet of narrative that the manner in which an event is narrated can drastically affect the experience of time in the story. Genette himself struggled with this reality, even though in his narratological project he tried to label it away. Simply put, a moment can be narrated over one hundred pages, and one hundred years can be narrated in one sentence. This is not a new insight, but it is crucially important to today's study of narrative. Knowing that such a wide variety of representations of time can occur in narrative, our concept of "temporality" in the story, the dependence on the concept that events can be ordered in a linear fashion, is greatly lessened. This is only taking the passage of time in the conventional sense. It is not that we have given up on the concept of temporality, but rather its inherent flexibility has by now been demonstrated, and concerning ourselves with linear time order is not very fruitful in reading anymore. At the same time, that does not mean that we do not retain a certain provisional concept of linear time order when reading.

Given issues such as these - that we now make meaning through the process of reading, not because of a certain end goal to the reading, that we are less concerned with the beginning (desire) and end (death) of the reading experience, and that we do not rely so strongly on chronological orderings of narratives - we need to extend Brooks's effort to work with concepts that will help us think through this sometimes frightening and indeterminate, but not chaotic, middle ground of narrative that we live with today. The best way to start to get a handle on this middle ground is to consider specific examples in a way that does not present them as representative. 


\section{Infinite Jest as an example of narrative middle ground}

Here I would like to briefly consider a small example from one of the most respected novels of the last 20 years, David Foster Wallace's Infinite fest (1996). One of the problems with using such an example is that traditional modes of criticism do not do justice to the novel form. Mikhail Bakhtin and György Lukács made this clear early in the $20^{\text {th }}$ century, but unfortunately we have not yet started to develop a criticism that can study the novel faithfully. One of the most important insights Bakhtin and Lukács have is that the method of making claims and then supporting those claims with evidence from the text does not work for novels. No one part of a novel can be representative of the whole. Novels are by nature complicated systems inextricably linked to lived life that cannot be excerpted without misrepresentation.

The part of Infinite fest that I analyze below involves the main character and a secondary character. It is not clear in this novel who the main character is, so below I provide a justification for my determination of one character as the main character. This status within the novel as a whole will inform the reading of the small part of the novel that follows. I also review the role of the secondary character in the novel for similar reasons, although that review is less contentious.

Infinite fest is widely considered one of the most important novels produced in English around the turn of the century, and David Foster Wallace is considered one of the writers that cannot be ignored in studying the fiction in English of that period. It is a huge novel, over 1 ooo pages, and it was a cultural sensation when it was released. Infinite fest contains many vignettes, urban legends, digressions, and other inclusions that do not have a clear relation to the overall structure of the novel and do not deal with any of the major characters. It is fair to generalize that despite these inclusions, the novel relies on two main story lines, each of which mostly follows one central character. Below I consider these two story lines in terms of how the overall novel is structured to determine which story line, and therefore which character, can be called the main story and character of the novel.

One main story line focuses on the Enfield Tennis Academy (ETA), and especially one tennis player at the academy named Hal Incandenza. The second story line centers around Ennet House, which is a halfway house for recovering drug addicts and alcoholics. Don Gately is a resident who becomes a staff member at the house, and he is the focus of this plot. For both of these plot lines, there is a clear main character and a chronological series of events 
that make up the story. Ennet House and the ETA are geographically close and eventually Don and Hal cross paths in the story. But the two plots are not clearly related. They share themes and methods of narration, but in terms of content they do not depend on each other.

Infinite fest is set in the near future, and in this future, calendar years are no longer numbered, but sponsored by corporations. Therefore, the name of a year is no longer its number, but, for example, the "Year of the Depend Adult Undergarment". This complicates determining the chronology of events in the book, since chapters are marked with dates, but one has to puzzle out the order of the sponsored years to put them and the chapters in chronological order (although one does know the relative order if events happened in the same year; months retain their traditional names). Also in this near future, the U.S.A., Canada, and Mexico have merged into the Organization of North American Nations, and the two main story lines take place near Boston.

Nine different sponsored years are named in the book, but most of the events take part in one year. The major exception is the very beginning of the story, the first 17 pages. This part is in the "Year of Glad", which is the year after the "Year of the Depend Adult Undergarment" (YDAU), which is the year when most of the action takes place. In this first section, Hal narrates (or serves as a focalizer with little narrator intervention) a scene where he is interviewing at the University of Arizona for a scholarship place on their tennis team. Apparently something is very wrong with the way $\mathrm{Hal}$ is acting, for it becomes obvious that the others in the scene are repelled by the way he speaks and acts, although from inside Hal the reader experiences a perfectly rational young man. Something is clearly wrong with Hal.

After this short first chapter, the story then goes back to YDAU, the previous year, when most of the events in the rest of the novel take place. Within this year the events are not chronological in the book, but with some rather simple arranging (aided by the fact that most of the sections are marked with the day or month) it quickly becomes clear which events happen in which order, and a causal relationship among events emerges. The Ennet House/Don Gately plot, however, is mostly chronological or otherwise rather easily arranged on the first reading.

What comes out in this analysis, however, is not how the events in the novel are arranged, but rather which events are absent, chronologically. The Don Gately story has no significant gaps, and moreover is told chronologically. However, in YDAU Hal is in no way afflicted like he is in the Year of Glad, there is no direct explanation as to why he becomes damaged, and any event 
or events that happened to him between the interview and the last YDAU event narrated in the book are not narrated. This means that, chronologically, the novel starts at the end, then jumps back to the beginning, and throughout the rest of the novel proceeds chronologically, stopping some months before the events in the first short chapter.

What happened to Hal between the end and the beginning of the novel is a crucially important event or series of events, but it is not narrated. In fact, its absence highlights its importance: it is too important to be included with the other events in the story. Even though the Gately plot takes up a lot of text and provides necessary input to the overall project of the novel, the fact that the novel is structured around the absence of what happened to $\mathrm{Hal}$ is the best evidence that the main character of the novel is Hal.

The analysis below focuses on $\mathrm{Hal}$ and his friend (perhaps his "best" friend) Michael Pemulis. Pemulis is a student at ETA with Hal, although during most the novel Hal performs much better on the tennis court than Pemulis. This is significant at ETA, for students are obsessed with their ranking relative to their classmates. In fact, it is suggested that Pemulis is on his way out. Pemulis comes from a more working-class background than $\mathrm{Hal}$ and the other students, and while he is just as extraordinarily intelligent as the others (in his own way), he also relishes engaging in illegal and unethical conduct. $\mathrm{He}$ masterminds a system of providing drug-free urine to students when officials come to do drug tests that is wildly lucrative. Pemulis confronts his drop in tennis performance by adding hallucinogens to his opponent's water. Pemulis's personality is to appear direct and forthcoming to officials and outsiders to cover up his questionable actions. But he also seems to be a loyal friend to $\mathrm{Hal}$, which is aided by the fact that they are not in competition in the school's tennis rankings.

One other note before the analysis: about 200 pages of Infinite fest is taken up by endnotes. There are references to these endnotes throughout the main text of the novel. The endnotes and the relation they have to the main text vary widely. Sometimes the note is conventional: providing a brief clarification of an issue relevant to the placing of the reference. But just as often the content of the endnote has no direct relevance to the place of the reference and moreover many of the endnotes are many pages long. This is a narrative strategy that Wallace uses to break up the typical way one reads through a novel. It also is another way to keep the reader on his or her toes, to force the reader not to assume the significance of any one part of the text, but rather to seriously think about significance in the context of the overall 
work. It also further complicates what it means to start a novel on the first page and end on the last page.

The part of Infinite Jest I would like to focus on is endnote 123. The reference to this endnote occurs about one-third of the way through the main text and is during a section that describes the unique ETA leisure-time game of Eschaton. The endnote describes how a certain mathematical formula works, which is pertinent to the location in the text, since Eschaton requires the direction of someone who has "a working knowledge of the Mean-Value Theory for Integrals" (323). The endnote reference appears immediately after these words. However, the endnote discusses this formula and how it is used in Eschaton in great detail - the endnote runs a full two pages - which seems unnecessary to the purposes of the main text.

The endnote opens thus: "Pemulis here, dictating to Inc" (1023). The two characters referred to are Michael Pemulis and Hal Incandenza ("Inc"), brilliant teenagers and good friends. It is asserted above that Hal is the (not undisputed) main character of the novel while Pemulis is a significant secondary character. The novel has multiple narrative lines and there are many characters in the novel who have nothing directly to do with either Hal or Pemulis.

In the parts of the novel that feature Hal, the narration is often focalized through his character, sometimes to the point that it seems we could call Hal the narrator of the text as well. Some have made the claim that Hal is the narrator - or a narrator - of the novel (Carlisle 204). The question of whether or not $\mathrm{Hal}$ is a narrator is to my mind largely moot since there has to be a narrator above $\mathrm{Hal}$ in any case (Greg Carlisle calls it a "meta-narrator" on page 205 of Elegant Complexity: A Study of David Foster Wallace's Infinite Jest), given the many other things going on in the novel that have little to do with Hal. If we have such a "meta-narrator", then Hal-as-narrator (or perhaps "subnarrator") can just as easily be called a focalizing character. The distinction between lower levels of narrator and characters presented as if they were narrators is largely irrelevant. Important for my point is that Hal does in places seem included into the narrative strategy in some integral form. In contrast, nowhere in the novel (other than perhaps this endnote) is Pemulis used as a focalizer, much less as a narrator.

The opening of this endnote (quoted above) indicates that Hal is taking dictation from Pemulis. This means that the words are Pemulis's and Hal is the means by which the words get transcribed. Why the content is presented in this way is not clear. However, Hal is not a transparent transcriber, even 
though - as Pemulis-through-Hal says - "Pemulis here, dictating to Inc, who can just sit there making a steeple out of his fingers and pressing it to his lip and not take notes and wait and like inscribe [sic] it anytime in the next week and get it verbatim, the smug turd" (1023, "[sic]" is in the original text). That is, Pemulis claims (through $\mathrm{Hal}$ ) that Hal has photographic memory, which seems reasonable given the descriptions of Hal's intellect throughout the novel. The "[sic]" in this quotation illustrates one of the ways Hal is not a transparent transcriber. It clearly comes from Hal: it is consistent with his character ( $\mathrm{Hal}$ would be confident in his ability to correct another's language use) and "sic" is not used by someone about their own speech. There are several such editorial insertions into the text, including an addendum. Particularly, there are a total of 15 instances of "[sic]" in the two-page endnote, some emphasized with italics, and one with a question mark attached. This indicates both Pemulis's lowerclass status (or his carelessness) and Hal's calm intellectual superiority. The addendum is in response to the characteristic Pemulis choice of an example measure in the theorem:

Let $\mathrm{d}$ be any constant, for computational reasons the closer to 1 the better, so like let d be the size of Hal's Unit.

Hal Incandenza's Addendum: In meters.

Michael Pemulis's Resumption: Very funny. (1024)

This endnote is an incredibly complicated narrative situation. Narratology provides little help to explain what kind of "grammar of narrative" this piece of text adheres to. However, and crucially, within the context of the novel, it makes perfect sense. According to the motivation and purpose of narratological study, this is simply not possible.

Let us attempt to examine this endnote in a narratological way to see where it gets us. Pemulis is dictating to Hal, which means that Pemulis is still "only" a character and not a narrator or even a focalizer. But Pemulis obviously has knowledge of his speech being recorded and written down for some purpose. That purpose, and therefore the whole situation of Pemulis dictating to $\mathrm{Hal}$ at all, is completely unclear. We are only left with this being written down for the novel itself, which makes absolute no narratological sense: a character who is not also a narrator being aware of the novel he is in.

While most of the words in this endnote are Pemulis's, the presentation of them is the responsibility of Hal, so we could call Hal the "writer" of the text and Pemulis is Hal's source. If Hal was not so implicated in the 
narration in much of the rest of the book, an easy narratological solution to this situation would be that the authorial narrator is making this scene up. We are rather accustomed to an authorial narrator entering and leaving a character's consciousness, sometimes focalizing through a character, sometimes observing that character from the outside. For this endnote to follow this logic, though, the narrator would have to present Hal as the "writer" of this text, and not as a focalizer. The endnote is not even in the third person; there is no text that indicates the narrator's presence at all, so she or he is invisible if present. But the presentation of $\mathrm{Hal}$ as "writer" but not focalizer or narrator at the same time highlights the narrator's position as narrator by making this text completely unique from the rest of the narration (because it is). The character of this part of the novel, while apparently disregarding the presence of a narrator, implicitly reveals the narrator as someone who would place this text in this novel at all. The simple fact that this text is in an endnote confirms the presence of the narrator: who but the (highest-level) narrator can create an endnote? This narrative logic is extremely specific to this endnote and would not obtain in any other part of this very long novel, and therefore it does not fulfill the goal of a narratological investigation, even in part.

In the end, in terms of narratology, there is not a logic that reasonably accounts for an excerpt like this alongside other parts of the novel that are both authorial and focalized narration. For narratology, there is a boundary here that should not be crossed, and it has been crossed. Our effort at coming to a narratological explanation of this passage force us to create a specific narrative system for only this short passage, and even that system does not quite work. If it did work, there would still be a problem since a narrative text, again in terms of narratology, cannot consist of a set of many different narrative grammars. There has to be one grammar that will explain the whole text. We should not be able to make sense of this endnote, it should simply not fit within the logic of the narrative of the story and novel as a whole. There is no grammar of narrative that we can rely on, no narratological explanation for this narrative.

These narratological problems would lead us to believe that this part of the novel must be read as chaotic and containing little meaning. But: this narrative does make sense. First of all, taken alone it would work fairly well as a short story, since the narrative situation is described at the beginning. Context would be lacking, but that is typical in short stories. By itself one would read it as a description of a conversation between two smart friends. This narrative also makes sense within the context of the story and novel. 
While it is unique, many of the other endnotes are also unique, so that one is not surprised by such uniqueness. In addition, the motivation for Pemulis's lecture is connected to the game of Eschaton that Pemulis is famous for promoting. A major chapter in the book describes a critical playing of this game, with Pemulis and Hal both present.

The footnote is also consistent with the two characters. The narrative situation is not repeated elsewhere, but the behavior and voice of the two characters is consistent with their personalities. Pemulis is not a focalizer anywhere else, but the voice he has here is exactly what we would expect. At the same time, in its small way, this endnote develops the story and characters. While we know that Pemulis is a math whiz, this endnote shows us his passion for the use of math, which we do not see as clearly elsewhere. Near the end of his dissertation on the formula, which includes the actual mathematical formulae and a graph, Pemulis interjects "This fucking works. [...] This is wicked. This is fucking elegant" (1024, emphasis in original). In the novel, we see Pemulis get excited about drugs and deception, but here is another side of his character. The endnote in fact contributes more to the illustration of these characters than other sections do and it is funny. Hal's addendum "in meters" when Pemulis suggests using Hal's penis as a standard of measurement is surprising but not out of character. Hal does not use this kind of crass humor in the parts that he narrates or focalizes, but it is not surprising that he, too, is influenced by the company of his friends. That humor is maybe the best proof, because it is funny within the book. It is funny because of the context of what we know about these characters from the rest of the novel. Although the endnote could be understood by itself, clearly it is not a set piece, it belongs in the novel.

Also it is not an "experimental" part of the text, explicitly meant to complicate narration. In fact, the feeling is much more that the reader should not worry too much about these narrative concerns, that the whole dictation/ endnote strategy is something of a joke, similar to writing "One time Pemulis explained this math concept to Hal, and this is what Pemulis said". That is, in reading this endnote, the feeling is that narrative is being simplified rather than complicated. We need a way to study narrative that can account for such a natural, effective, and common way of telling stories as this. 


\section{Conclusion}

Narratology is based on a project to create or discover a "grammar of narrative". One of the assumptions that such a project makes is that any one piece of narrative has a consistent narrative strategy, or at the very least has an inconsistent narrative strategy that can be explained in a consistent way. This is an assumption both about narrative and the study of narrative. Narrative that is not consistent or explainable in this way cannot be narrative: it cannot be understood in the way that we expect to understand stories. It might be like abstract poetry, where there is a suggestion of meaning, but there need not be characters, scene, events, progression, etc. But, according to narratology, a text that cannot be explained in a consistent way cannot be a narrative.

What the example from Infinite fest shows, though, is that narrative can indeed be inconsistent and unable to be explained by narratology but still have meaning and be understood as a narrative by readers. The typical approach of scholars of narrative to texts like Infinite fest is to make a series of claims for the consistency of the text, citing examples from the text to support their cases. Of course, this method produces studies that are internally consistent. However, this is the method rejected by Mikhail Bakhtin and György Lukács, for any one novel will offer evidence for many different claims of consistency. Because of this, the scholarship on the narratology of such a text continues ad infinitum, no one able to prove any of the studies wrong nor able to prove their own cases correct, but both able to construct criticism that makes consistent arguments. The problem is that the arguments are not valid in a scientific sense. I have shown in my example that parts of texts can be picked out to show how a narrative is inconsistent as well.

The idea of a toolbox of terms and concepts with which to describe narrative in a consistent and coherent way is enticing. Narrative, and the novel in particular, seem to need to have a consistent enough structure to allow multiple readers to come to similar readings of the same text, and it seems that we should be able to identify that consistent structure to employ in criticism. But we should have learned from fiction of the past 100 years (at least) that such consistent and coherent description is not possible, even though certainly readers have similar experiences of the same text. Genette has not and cannot be proven wrong, because all of the components of his toolbox work at least some of the time, and some of them work the vast majority of the time, especially if you look at the right works, and especially the right parts of works, in the right way. Genette's structure continues to be 
criticized and added on to because there is no way to stop the proliferation of attempts to get the structure right. But by now we can see that this approach has produced a toolbox that is more and more complicated and less and less useful. We do not replace old narrative concepts with new, better ones. We merely add new ones onto the old ones.

I suggest that such criticism does not lead us to a better or deeper understanding of the text at hand (which does not have to be a novel) or narrative as a field of study. Novels like Infinite Jest have simply not yet begun to be studied in an appropriate way. We have not yet started to answer the question of why Infinite fest does not follow our current theory of narrative but still seems to make sense to a lot of readers (including but not limited to scholars) as a story. Moreover, while Infinite fest is an important text, it is far from the only example - especially of novels - in recent decades that have this character.

It is not my purpose here to suggest what that appropriate criticism or theory of narrative would or should be. I suspect that it will involve not only a new idea for a theory of narrative and a consequent different way to criticize narrative, but also a different mode of academic and literary scholarship and criticism in general. This seems to me something that should be formed by communal effort. A good beginning point would be to take up the challenge that Bakhtin and Lukács laid down almost 100 years ago and start studying novels in ways that respect the novel form. This would most effectively be done by studying contemporary novels, which are closer to our sense of lived reality.

\section{Works Cited}

Bakhtin, Mikhail Mikhailovich. The Dialogic Imagination. 1975. Ed. Michael Holquist. Trans. Caryl Emerson and Michael Holquist. Austin: University of Texas Press, 1981.

Barthes, Roland and Lionel Duisit. "An Introduction to the Structural Analysis of Narrative." New Literary History 6 (1975): 237-272.

Barthes, Roland. "The Death of the Author." In Image Music Text. Trans. Stephen Heath. London: Fontana Press, 1977.

---. S/Z. 1970. Trans. Richard Miller. New York: The Noonday Press, 1993. Brooks, Peter. Reading for the Plot: Design and Intention in Narrative. Cambridge: Harvard University Press, 1984 .

Carlisle, Greg. Elegant Complexity: A Study of David Foster Wallace's Infinite Jest. Los Angeles: Sideshow Media Group, 2007. 
Culler, Jonathan. "Foreword." In Gérard Genette, Narrative Discourse: An Essay in Method. 1972. Trans. Jane E. Lewin. Ithaca: Cornell University Press, 1980.

Genette, Gérard. Narrative Discourse: An Essay in Method. 1972. Trans. Jane E. Lewin. Ithaca: Cornell University Press, 1980.

---. Narrative Discourse Revisited. 1983. Trans. Jane E. Lewin. Ithaca: Cornell University Press, 1988.

Greimas, Algirdas Julien. On Meaning: Selected Writings in Semiotic Theory. Trans. Paul J. Perron and Frank H. Collins. Minneapolis: University of Minnesota Press, 1976.

Kermode, Frank. The Sense of an Ending: Studies in the Theory of Fiction. Oxford: Oxford University Press, 1966.

Lukács, György. The Theory of the Novel. 1920. Trans. Anna Bostock. Cambridge: MIT Press, 1973.

Propp, Vladimir. The Morphology of the Folktale. 1928. Ed. Louis A. Wegner. $2^{\text {nd }}$ ed. Trans. Laurence Scott. Austin: University of Texas Press, 1977.

Ricoeur, Paul. Time and Narrative, Volume 1. 1983. Trans. Kathleen McLaughlin and David Pellauer. Chicago: University of Chicago Press, 1984 .

--- Time and Narrative, Volume 2. 1984. Trans. Kathleen McLaughlin and David Pellauer. Chicago: University of Chicago Press, 1985.

---. Time and Narrative, Volume 3. 1985. Trans. Kathleen Blamey and David Pellauer. Chicago: University of Chicago Press, 1988.

Rimmon-Kenan, Shlomith. Narrative Fiction: Contemporary Poetics. London: Routledge, 1983 .

Todorov, Tzvetan. The Poetics of Prose. Trans. Richard Howard. Ithaca: Cornell University Press, 1977.

Wallace, David Foster. Infinite fest. New York: Back Bay Books, 1996. 